\title{
Molecular Docking Study of Mangosteen (Garcinia mangostana L.) Xanthone-Derived Isolates as Anti Androgen
}

\author{
Cecep Suhandi ${ }^{1, *}$, Ersa Fadhilah ${ }^{1}$, Nurfianti Silvia ${ }^{1}$, Annisa Atusholihah ${ }^{1}$, \\ Randy Rassi Prayoga ${ }^{1}$, Sandra Megantara ${ }^{2}$, Muchtaridi ${ }^{2}$ \\ ${ }^{1}$ Bachelor Pharmacy Program, Faculty of Pharmacy, Padjadjaran University, Sumedang, Indonesia \\ ${ }^{2}$ Department of Pharmaceutical Analysis and Medicinal Chemistry, Faculty of Pharmacy, Padjadjaran University, \\ Sumedang, Indonesia
}

\begin{abstract}
Androgen receptor (AR) is the member of steroid hormone receptor involved in the progression of prostate cancer growth due to receptor over-activation. On the other hand, mangosteen (Garcinia mangostana L.) as a medicinal plant contains xanthone-derived compounds which were known to have cytotoxic activity towards any types of human cancer cells. This research aims to determine xanthone-derived isolates potency from mangosteen as AR antagonists. The study was carried out through molecular docking assay utilizing AutoDock 4.2.6 using androgen receptor obtained from PDB ID 2AM9, testosterone as native ligand, and bicalutamide, flutamide, and nilutamide as reference. The results indicated that three isolates (1,3,7-trihydroxy-2,8-di-(3-methylbut-2-enyl)xanthone, mangostinone, and trapezifolixanthone) have the highest potency to be AR antagonist seen from the lower bondfree energy value than all of reference ligand. The lowest bond-free energy was provided by mangostinone with a $\Delta G$ value of $-10.05 \mathrm{kcal} / \mathrm{mol}$. However, the highest difference of residual amino acids interaction with testosterone and similar interaction with bicalutamide was provided by 1,3,7-trihydroxy-2,8-di-(3-methylbut-2-enyl)xanthone, with five different amino acids with testosterone and nine similar amino acids with bicalutamide, respectively. Interestingly, 1,3,7-trihydroxy-2,8-di-(3-methylbut-2-enyl)xanthone has similar hydrogen bond with the key residue amino acids of AR (705-Asn and 711-Gln) which indicates probably partial agonist activity while mangostinone has the highest amount of hydrogen bond in the absence of hydrogen bond towards key residual amino acids of AR. The results concluded that three specific derived-xanthone compounds were predicted to have activity as AR antagonists.
\end{abstract}

Keywords: Prostate cancer, Androgen receptor, Mangosteen, Xanthone, Molecular docking.

\section{INTRODUCTION}

Prostate cancer is the mostly cancer type diagnosed among men worldwide (Singh, Baruah and Sharma, 2017). It is well established that natural androgens, such as testosterone and dihydrotestosterone (DHT), has major role in progression of androgen-dependent prostate cancer through ago- nist action towards Androgen Receptor (AR) (Song, et al., 2012). AR is the member of steroid hormone receptor which contains hormone-binding domain

Submitted: December 6, 2020

Revised: January 20, 2021

Accepted: January 21, 2021

*Corresponding author: cecep17001@mail.unpad.ac.id 
and DNA-binding domain. AR activation results in translocation of this receptor to the nucleus and regulates specific gene, such as NK3 transcription factor locus 1 (NKX3.1) and prostate-specific antigen (PSA) (Setlur and Rubin, 2005; Song, et al., 2012). Although many anti androgens has been established, including bicalutamide, flutamide, and nilutamide, the problem of unspecific cytotoxicity effect and cancer recurrence after drug intake remains a major hurdle for establishing effective therapy (Peng, et al., 2019). In addition, bicalutamide as a non-steroidal anti androgen also shows partial agonist properties during long-term androgen ablation (Culig, et al., 1999; Bohl, et al., 2005). Therefore, many researches were directed to investigate phytochemical constituents which are contained in medicinal plants. In addition, structure-Based Drug Design (SBDD) can be an appropriate strategy in predicting the type of physiological activity that occurs through knowing the key residual amino acids interaction which could differ between agonist and antagonist activity (Tan, et al., 2014).

Mangosteen (Garcinia mangostana L.) is a native medicinal plant from South East Asia and has been researched for many pharmacological activity of the disease (Ovalle-Magallanes, Eugenio-Pérez and Pedraza-Chaverri, 2017). It has several biological effects, such as anti-inflammation, antioxidant, anti-proliferative, pro-apoptotic, neuroprotective, and hypoglycemic in managing diabetes (Siridechakorn, et al., 2012; Fu, et al., 2014; Wang, et al., 2015). A study stated that methanol extract from the pericarp of mangosteen has an anti-proliferative effect towards SKBR3 human breast cancer cell by inducing apoptosis. Another investigation showed that the pericarp of mangosteen containing variety of xanthones also has anti-proliferative activity against human leukemia HL60 cells (Obolskiy, et al., 2009).

The main phytochemicals that are responsible for mangosteen's activity are isoprenylated xanthones, major secondary metabolites which are contained in mangosteen (Tiang, et al., 2020). Xanthone compounds from mangosteen were known had anticancer and anti-proliferative activity in leukemia which is has same few regulation as well as brain, colorectal, breast, and prostate cancers (Chao, et al., 2011). Therefore, this study aims to investigate and determine potential xanthone isolates from mangosteen as anti-androgen. This study utilizing structure-based approach using molecular docking technique compared to known AR antagonists including bilutamide, flutamide, and nilutamide.

\section{METHODS}

The hardware used was the MSI GL62m 7RDX with an Intel ${ }^{\mathrm{TM}}$ 17-7700HQ+HM175@3.8 $\mathrm{GHz}$ and Windows 10 Home 64-bit operating system. This research used software, including ACD/ChemSketch Software 14.0 (Free Version), LigandScout 4.4.3, AutoDockTools 1.5.6 and AutoDock 4.2.6 software from The Scripps Research Institute, and BIOVIA Discovery Studio 2017 R2 Client (Helgren and Hagen, 2018; Torres, Sodero and Jofily, 2019).

Materials were used for this research including target protein structure, test ligands structures, and references ligands structures. Three-dimensional structure of target protein (receptor) was obtained from Protein Data Banks website (http:// rcsb.org). The test ligands used were 14 xanthones derived compounds from mangosteen (Garcinia mangostana L.) as shown in Figure 1 consisting of 1,3,7-trihydroxy-2,8-di-(3-methylbut-2-enyl) xanthone (1); 1,5,8-trihydroxy-3-methoxy-2[3methyl-2-butenyl]xanthone (2); 6-deoxy-gammamangostin (3); 7-O-demethyl mangostanin (4); 8-deoxygartanin (5); garcinone B (6); garcinone $\mathrm{E}$ (7); gartanin (8); mangostanin (9); mangostenone D (10); mangostinone (11); padiaxanthone (12); tovophylline A (13); and trapezifolixanthone (14) (Yang, et al., 2017). The reference ligands, including bicalutamide, flutamide, and nilutamide, 




(1)



(5)



(9)

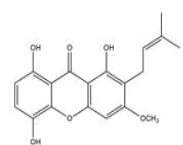

(2)

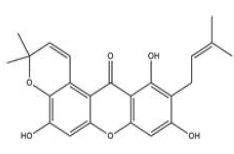

(6)



(10)

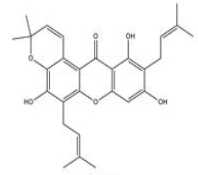

(13)

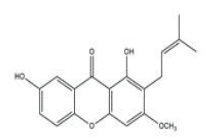

(3)

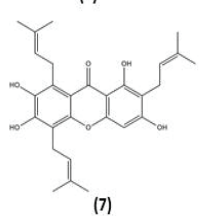

(7)

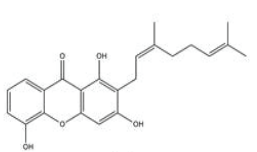

(11)

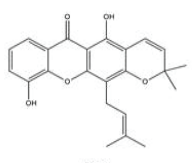

(14)

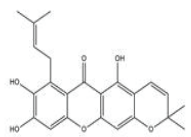

(4)

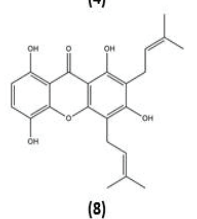

(8)

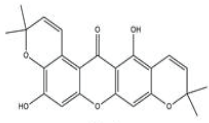

(12)

Figure 1. Structure of known xanthone-derived isolates from mangosteen (Yang, et al., 2017).

were small-molecule androgen receptor antagonists that has been used and was marketed in the treatment of prostate cancer.

The two-dimensional structure of all ligands was depicted using ACD/ChemSketch 14.0. Ideal 3D structure conformation of all test ligands and references was provided by performing energy minimization using Molecular Mechanic Force Field-94 (MMFF94) minimization in LigandScout 4.4.3, which would be providing ideal conformation of these compounds as exist is in nature (Vanommeslaeghe, Guvench and MacKerell Jr., 2015). Optimized 3D structures of all test ligands and references then saved in .pdb format. In this study, docking program was run using AutoDock 4.2.6. Before running process, all ligands and receptor were prepared by giving the specific charge and torque for ligands by default utilizing software AutoDockTools 1.5.6 (Forli, et al., 2016). Docking simulation results then visualized using Discovery Studio Visualizer 19.1.0 to analyze molecular interaction between ligands and residual amino acids from receptor.

The structure of androgen receptor (AR) was obtained from the Protein Data Bank (PDB) website (http://www.rscb.org) with PDB ID 2AM9. The receptor has a resolution of $1.64 \AA$ and bind to a nature ligand of testosterone, a steroidal hormone

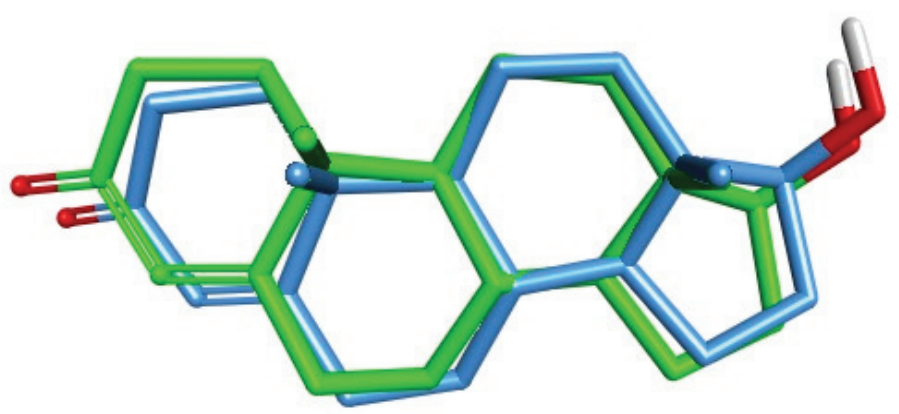

Figure 2. Overlay ligands after re-docking (green) and co-crystal ligands from crystallography (blue) at 2 AM9 complex; RMSD $=0.79 \AA$ A. 


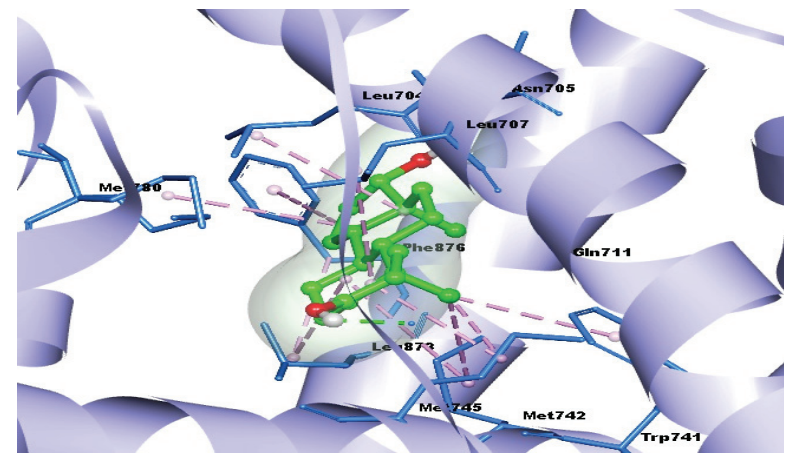

Figure 3. Interactions of testosterone in amino acid residues from AR receptor.

that is known to have an agonist action towards AR (Pereira de Jesus-Tran, et al., 2006).

Although this study aimed to find AR-antagonist compounds, the use of AR-testosterone complex which are agonist was preferred over AR-bicalutamide complex because as previously explained that bicalutamide exhibits partial agonist properties (Culig, et al., 1999). Thus, the use of the AR-bicalutamide complex could yield biased predictive conclusions regarding the pharmacological activity of the test compound. The receptor was downloaded in .pdb, removed the waters and another portion, added by non-polar portion of hydrogen group, and given by the Kollman charge using software AutoDockTools 1.5.6. The binding domain of the AR was the active site portion which was bind to AR agonist, in this case, testosterone (McEwan and Brinkmann, 2020).

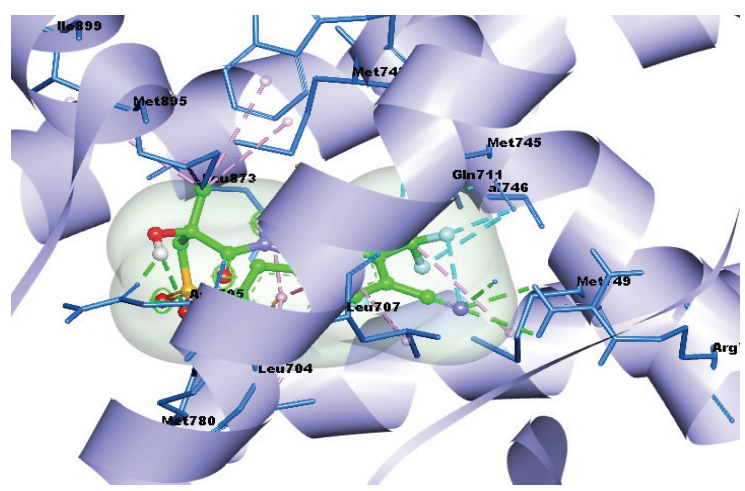

Figure 4. Interactions of bicalutamide in amino acid residues from AR receptor.
The method validation process was carried out through re-docking process of testosterone as nature ligand which was extracted from the 2AM9 complexes towards AR. Before re-docking, testosterone was added by the non-polar portion of hydrogen group, given with Gasteiger charge, torque and adjusting rotational bond, then saved as file in the .pdbqt. The nature ligand was then re-process with molecular docking at center of ligand in the grid box coordinate and size predetermined from molecular direction (Ferreira, et al., 2015; ValdésTresanco, et al., 2020). Root Mean Square Deviation (RMSD) then observed from the validation

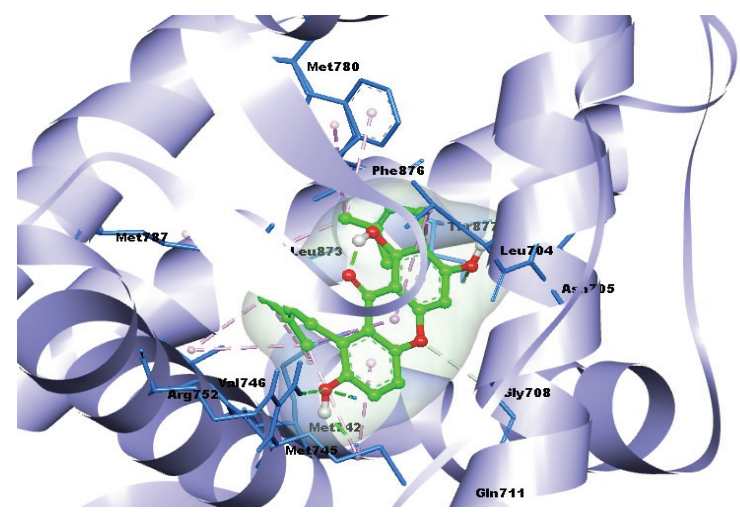

Figure 5. Interactions of 1,3,7-trihydroxy-2,8-di-(3methylbut-2-enyl)xanthone in amino acid residues from AR receptor.

process as parameter which could value validity of the method. The RMSD score explains the average difference in distance of each atom from ligand after re-docking process. The small of RMSD score indicated that the validity of the docking method was high and has higher similar results with crystallography results. The requirement of RMSD score was less than $2 \AA$, which denoting a valid docking method (Puratchikody, et al., 2016; Pagadala, Syed and Tuszynski, 2017).

Docking process for all test and reference ligands performed with the same steps as the redocking stage (validation) with similar size and coordinate of the grid box. The main parameter observed in docking simulation with AutoDock 4.2.6 was the free binding energy $(\Delta \mathrm{G})$ as affinity 


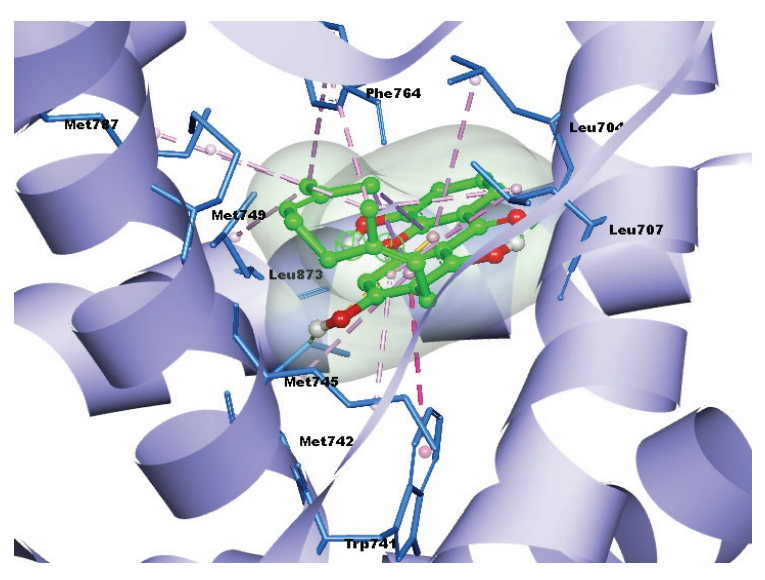

Figure 6. Interactions of mangostinone in amino acid residues from $A R$ receptor.

strength marker and residual amino acids interaction as interaction marker (Clark and Labute, 2007; Forli, et al., 2016). The more negative $\Delta \mathrm{G}$ indicated the higher ligand affinity towards binding site of the specific receptor (Ryde and Söderhjelm, 2016). The residual amino acids interaction of all test ligand then compared with reference to evaluate the similarity of interaction. The more similar residual amino acids interaction indicated that the test ligand will have a similar activity with the reference (Ferreira, et al., 2015).

\section{RESULTS}

Re-docking result from this research was provided RMSD score of $0.79 \AA$, indicated that the docking method using 2AM9 complexes was valid for docking purpose. Visualization of ligand overlays resulting after re-docking process towards $\mathrm{AR}$ is depicted in Figure 2. Other parameters used in the re-docking stage, including size and grid box coordinate, $\Delta \mathrm{G}$ and residual amino acids interaction as shown in Table 1.

The docking of the fourteen test ligands and reference ligands showed promising results that several compounds have higher affinity than reference. There are no compounds which have higher affinity than testosterone which acts as agonist of $\mathrm{AR}$, including all of reference ligands. Bicalutamide has higher affinity than other reference ligands, with a value of $-9.72 \mathrm{Kcal} / \mathrm{mol}$. Since AR-bicalutamide complex also available with PDB ID: 1Z95, this result possess similar hydrogen bond interaction with the prediction from crystallography reference, especially towards 705-Asn, 711-Gln, and 752-Arg (Bohl, et al., 2005). Isolate 1 (1,3,7-trihydroxy-2,8-di-(3-methylbut-2enyl)xanthone), isolate 11 (mangostinone), and iso-

Table 1. Results of the re-docking process.

\begin{tabular}{|c|c|}
\hline Parameter & Value \\
\hline PDB ID & 2AM9 \\
\hline Nature Ligand & Testosterone \\
\hline Grid box size $(\AA \bar{A})$ & $40 \times 40 \times 40$ \\
\hline \multirow{3}{*}{ Grid box coordinate } & $x=26.907$ \\
\hline & $y=2.557$ \\
\hline & $z=5.181$ \\
\hline RMSD (Ă) & 0.79 \\
\hline$\Delta \mathrm{G}(\mathrm{Kcal} / \mathrm{mol})$ & -11.98 \\
\hline \multirow[t]{10}{*}{ Residual amino acids interaction } & 704-Leu** \\
\hline & 705-Asn* \\
\hline & 707-Leu** \\
\hline & 7II-Gln* \\
\hline & 74I-Trp** \\
\hline & 742-Met ${ }^{* *}$ \\
\hline & 745-Met** \\
\hline & 780-Met** \\
\hline & 873-Leu** \\
\hline & 876-Phe*** \\
\hline
\end{tabular}

*Hydrogen Bond; **Alkyl/Pi-Alkyl Interaction 
late 14 (trapezifolixanthone) showed lower value of $\Delta \mathrm{G}$ than bicalutamide as presented in Table 2. Practically, it indicates that these three compounds have the potential as bicalutamide, flutamide, and nilutamide as antagonists at AR binding sites. Specifically, mangostinone has the bigger difference of the $\Delta \mathrm{G}$ value with bicalutamide than others with a value of $0.33 \mathrm{Kcal} / \mathrm{mol}$.

Observations of amino acid residues also showed promising results, as presented in Table 2. 1,3,7-trihydroxy-2,8-di-(3-methylbut-2-enyl)xanthone, mangostinone, and trapezifolixanthone each have a different amount of amino acid residues from testosterone, 5, 3, and 4, respectively. 1,3,7-trihydroxy-2,8-di-(3-methylbut-2-enyl)xanthone also has higher residual amino acids similarity with bicalutamide than two others with nine similar amino acids. Furthermore, all of residual amino acids interaction between testosterone, bicalutamide, those three compounds and AR receptor were shown in Figure 3 until Figure 7.

\section{DISCUSSION}

The docking simulation was established by using Lamarckian genetic algorithm in value of 50 . Genetic algorithm explains about how much degree of freedom of the interaction results in number of conformation (Hetényi and Spoel, 2002). In addition, other parameters were set as the default values of AutoDock 4.2.6. The value of genetic algorithm was increased from 10 to 50 to enhance the reliability of the docking process which was performed (Forli, et al., 2016). This is based on a study which states that at genetic algorithm values below 50 there was fast increase in correct sites, while above a value of 50 indicates an insignificant increase (Hetényi and Spoel, 2002). Docking simulation was performed using similar configuration settings with the re-docking (validation) process with only changes in the ligand file used. The most interesting finding is that from all compounds, the three that have an affinity value that has lower $\Delta \mathrm{G}$

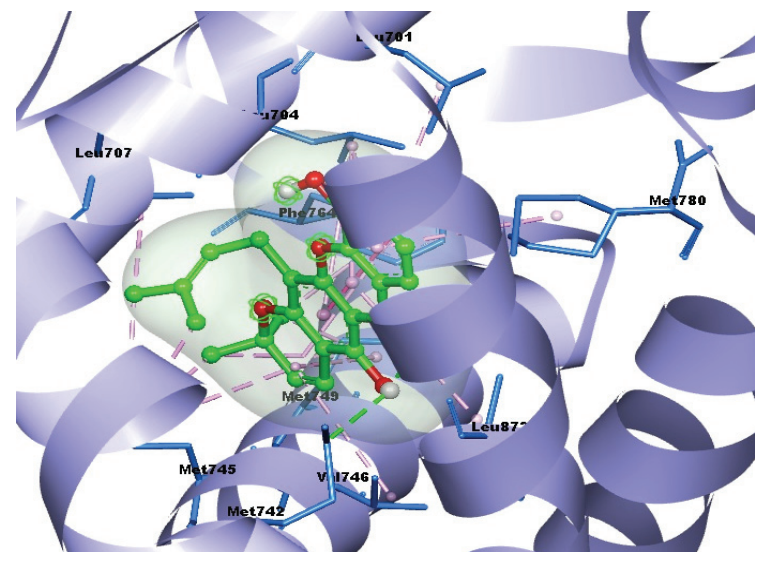

Figure 7. Interactions of trapezifolixanthone in amino acid residues from AR receptor.

value than bicalutamide as marketed AR antagonist and can be compared with testosterone as nature ligand. The hydrogen bond interaction form with 705-Asn and 711-Gln amino acid residues is the key residue of AR which is responsible for agonist activity through modulating an 'active conformation' that primes the receptor for coactivator binding to an AF2 region comprised of H3, H4, and H12 (Tan, et al., 2015). The isolate 11 (mangostinone) and isolate 14 (trapezifolixanthone) does not have hydrogen bonds towards key amino acids residues as explain before and were predicted would have better antagonist activity than bicalutamide because of lower value of $\Delta \mathrm{G}$ than bicalutamide. However, no one compounds which has lower $\Delta \mathrm{G}$ value than testosterone.

In residual amino acids interaction, the highest difference types of amino acids interactions compared to testosterone has provided by isolate 1 (1,3,7-trihydroxy-2,8-di-(3-methylbut-2-enyl)xanthone) with five different amino acids interaction. In addition, 1,3,7-trihydroxy-2,8-di-(3-methylbut2-enyl)xanthone also showed a high similarity to bicalutamide with nine similar amino acids interaction. The high amino acid residue differences with testosterone and similarity with bicalutamide of 1,3,7-trihydroxy-2,8-di-(3-methylbut-2-enyl)xanthone increases the probability that this compound 
Indonesian Journal of Cancer Chemoprevention, February 2021

ISSN: 2088-0197

e-ISSN: 2355-8989

Table 2. Results of the docking simulation of test and reference ligands towards AR receptor.

\begin{tabular}{|c|c|c|c|}
\hline \multirow{2}{*}{ Ligand } & \multirow{2}{*}{$\Delta \mathbf{G}(\mathrm{Kcal} / \mathrm{mol})$} & \multicolumn{2}{|c|}{ Residual Amino Acid Interactions } \\
\hline & & Hydrogen Bond & Others \\
\hline Bicalutamide & -9.72 & 705-Asn, 7|I-Gln, 752-Arg & $\begin{array}{l}\text { 704-Leu*, 707-Leu*, 74I-Trp*, 742-Met', 745-Met', } \\
\text { 746-Val*, 749-Met*, 780-Met**, 873-Leu*, 895-Met*, } \\
\text { 899-Ile* }\end{array}$ \\
\hline Flutamide & -7.67 & 752-Arg & $\begin{array}{l}\text { 701-Leu*, 704-Leu*, 707-Leu*, 745-Met', 746-Val*, } \\
\text { 749-Met*, 764-Phe**, 895-Met* }\end{array}$ \\
\hline Nilutamide & -8.92 & 705-Asn, 708-Gly, 752-Arg & $\begin{array}{l}\text { 70I-Leu*, 704-Leu*, 707-Leu*, 745-Met', 746-Val*, } \\
\text { 749-Met*, 764-Phe** }\end{array}$ \\
\hline Isolate I & -9.92 & $\begin{array}{l}\text { 705-Asn, 7II-Gln, 752-Arg } \\
\text { 877-Thr }\end{array}$ & $\begin{array}{l}\text { 704-Leu*, 708-Gly”, 742-Met*, 745-Met*, 746-Val*, } \\
\text { 780-Met*, 787-Met*, 873-Leu*, 876-Phe* }\end{array}$ \\
\hline Isolate 2 & -8.91 & 745-Met & $\begin{array}{l}\text { 70I-Leu*, 704-Leu*, 705-Asn", 742-Met**, } 749- \\
\text { Met*, 780-Met*, 873-Leu*, 876-Phe*, 880-Leu*, 895- } \\
\text { Met* }\end{array}$ \\
\hline Isolate 3 & -9.38 & 877-Thr & $\begin{array}{l}\text { 707-Leu*, 742-Met***, 746-Val*, 749-Met*, 764-Phe*, } \\
\text { 787-Met***, 873-Leu* }\end{array}$ \\
\hline Isolate 4 & -4.61 & 704-Leu & $\begin{array}{l}\text { 70I-Leu*, 707-Leu*, 742-Met } \\
\text { Met*o, 764-Phe*, 780-Met*, 873-Leu*, 880-Leu*, } 889- \\
\text { Val*, 89I-Phe* }\end{array}$ \\
\hline Isolate $\mathbf{5}$ & -9.56 & 704-Leu, 780-Met & $\begin{array}{l}\text { 70I-Leu*, 705-Asn”, 707-Leu*, 742-Met*, 745-Met*, } \\
\text { 746-Val*, 749-Met*, 764-Phe*, 787-Met*, 873-Leu*, } \\
\text { 880-Leu* }\end{array}$ \\
\hline Isolate 6 & -6.45 & 873-Leu & $\begin{array}{l}\text { 704-Leu*, 707-Leu*, 745-Met*, 746-Val*, 749-Met*, } \\
\text { 764-Phe*, 780-Met**, 787-Met*, 89I-Phe*, 895- } \\
\text { Met*, 899-Ile* }\end{array}$ \\
\hline Isolate 7 & 0.52 & - & $\begin{array}{l}\text { 70I-Leu*, 704-Leu*, 707-Leu*, 708-Gly", 7I I-GIn"', } \\
\text { 742-Met*, 745-Met*, 746-Val*, 749-Met*, 780-Met"', } \\
\text { 787-Met*, 873-Leu**, 876-Phe*, 880-Leu*, 895-Met*' }\end{array}$ \\
\hline Isolate 8 & -8.57 & 705-Asn, 780-Met &  \\
\hline Isolate 9 & -5.11 & 704-Leu, 873-Leu & $\begin{array}{l}\text { 70I-Leu*, 707-Leu*, 745-Met*, 749-Met*, 764-Phe*, } \\
\text { 780-Met*, 876-Phe*, 880-Leu*, 889-Val*, 89I-Phe** }\end{array}$ \\
\hline Isolate 10 & -6.6 & 705-Asn, 7II-Gln & $\begin{array}{l}\text { 704-Leu*, 707-Leu*, 742-Met*, 745-Met*, 749-Met* } \\
\text { 764-Phe*, 780-Met*, 873-Leu*, 876-Phe*, 895-Met*** }\end{array}$ \\
\hline Isolate I I & -10.05 & 704-Leu, 742-Met & $\begin{array}{l}\text { 707-Leu*, 74I-Trp**, 745-Met*, 749-Met*, 764-Phe*, } \\
\text { 787-Met*, 873-Leu* }\end{array}$ \\
\hline Isolate 12 & -1.36 & - & $\begin{array}{l}\text { 70I-Leu*, 704-Leu*, 707-Leu*, 745-Met*, 749-Met*, } \\
\text { 764-Phe*, 780-Met*1*k, 876-Phe*, 880-Leu*, 889-Val*, } \\
\text { 89।-Phe* }\end{array}$ \\
\hline Isolate 13 & 8.89 & - & $\begin{array}{l}\text { 70I-Leu*, 704-Leu*, 705-Asn"', 707-Leu*, 745-Met*, } \\
\text { 764-Phe**, 770-Phe*, 780-Met”, 784-Cys*, 787- } \\
\text { Met"***, 880-Leu*, 873-Leu*, 889-Val*, 89I-Phe* }\end{array}$ \\
\hline Isolate 14 & -9.87 & 742-Met & $\begin{array}{l}\text { 701-Leu*, 704-Leu*, 707-Leu*, 745-Met*, 746-Val*, } \\
\text { 749-Met*, 764-Phe**, 780-Met*, 873-Leu* }\end{array}$ \\
\hline
\end{tabular}

*Alkyl/Pi-Alkyl Interaction; **Pi-Sigma/Pi-Pi T Shaped Interaction; ***Pi-Sulfur/Sulfur-X Interaction; 'Halogen Interaction; "Carbon Hydrogen Bond, "'Unfavorable Bump 
would have activity as an AR antagonist with a similar mechanism of action of bicalutamide. It also suggests that this compound may have partial agonist activity as demonstrated by bicalutamide due to the same hydrogen bond towards key residual amino acids of AR (705-Asn and 711-Gln). Moreover, the value of $\Delta \mathrm{G}$ of this compound itself is lower than bicalutamide and trapezifolixanthone but higher than mangostinone. However, the significant number of interactions of amino acid residues will undoubtedly enhance the probability of similar types of interactions, while also exactly enhance ligand affinity (Wang, Mcinnes and Zhu, 2013; Ferreira, et al., 2015). The greatest finding from this study is that mangostinone has the lowest value of $\Delta \mathrm{G}$ than bicalutamide and two others and also has two hydrogen bonds to different amino acids with key amino acids of AR. It suggests that mangostinone has the greatest potency to be an antagonist of AR than two others with the absence of partial agonist activity.

Each xanthone isolate possess different binding interaction towards AR. It is the uniqueness of the SBDD strategy while we have compounds from the same group does not guarantee the same interaction. It can occur because of the kind and orientation of substituents involved in the structure. The main difference in the interactions between 1,3,7-trihydroxy-2,8-di-(3-methylbut-2-enyl)xanthone and two others is due to the orientation of the alkyl groups that occurs due to the hydrophobic effect of the alkyl group. The location of alkyl groups affect number of residual amino acids interaction which occurred. However, even though 1,3,7-trihydroxy-2,8-di-(3-methylbut-2-enyl)xanthone has more interactions than two others, it showed lower affinity than mangostinone. It is interesting to observe whether two other promising compounds would also produce similar interactions with 1,3,7-trihydroxy-2,8-di-(3-methylbut-2-enyl)xanthone, considering the value of $\Delta \mathrm{G}$ that was relatively low. However, through this simple molecular docking study, the results obtained were limited to predictions or hypotheses as an initial pathway in drug discovery. In its natural occurrence, this hypothesis may be relevant or not. Therefore, other advance computational research can be carried out as a reinforcement of the hypothesis prior to experimental study, both in vitro and in vivo.

\section{CONCLUSION}

This research successfully demonstrated that among the xanthone isolates of mangosteen (Garcinia mangostana L.), the highest potency for AR antagonists was provided by 1,3,7-trihydroxy-2,8-di-(3-methylbut-2-enyl)xanthone, mangostinone, and trapezifolixanthone. The antagonist activity was hypothesized in the absence of hydrogen bond of the three compounds, except 1,3,7-trihydroxy-2,8-di-(3-methylbut-2-enyl)xanthone, towards key residual amino acids of AR (705-Asn and 711-Gln). While 1,3,7-trihydroxy2,8-di-(3-methylbut-2-enyl)xanthone has showed very high amino acid interaction similarities with the reference ligand and differences with testosterone as agonist agent, but the lowest free energy binding established by mangostinone, respectively. Furthermore, further both in vitro and in vivo research including toxicity assay can be carried out to prove the potency of the three compounds as AR antagonists.

\section{ACKNOWLEDGMENT}

This research is part of a series of research in Drug Discovery and Development at the Faculty of Pharmacy, Padjadjaran University, which was guided by Prof. apt. Muchtaridi, Ph.D. and Dr. apt. Sandra Megantara, M.Farm.

\section{REFERENCES}

Bohl, C.E., Gao, W., Miller, D.D., Bell, C.E. and Dalton, J.T., 2005, Structural basis for antagonism and resistance of bicalutamide in prostate cancer, PNAS, 102(17), 6201-6206.

Chao, A-C., Hsu, Y-L., Liu, C-K. and Kuo, P-L., 2011, 
Alpha-Mangostin, a Dietary Xanthone, Induces Autophagic Cell Death by Activating the AMP-Activated Protein Kinase Pathway in Glioblastoma, Journal of Agricultural and Food Chemistry, 59(5), 2086-2096.

Clark, A.M. and Labute, P., 2007, 2D Depiction of Protein-Ligand Complexes, Journal of Chemical Information and Modeling, 47(5), 1933-1944.

Culig, Z., Hoffmann, J., Erdel, M., Eder, I.E., Hobisch, A., Hittmair, A., Bartsch, G., et al., 1999, Switch from antagonist to agonist of the androgen receptor blocker bicalutamide is associated with prostate tumour progression in a new model system, British Journal of Cancer, 81(2), 242-251.

Ferreira, L.G., Santos, R.N.D., Oliva, G. and Andricopulo, A.D., 2015, Molecular Docking and Structure-Based Drug Design Strategies, Molecules, 20(7), 13384-13421.

Forli, S., Huey, R., Pique, M.E., Sanner, M.F., Goodsell, D.S. and Olson, A.J., 2016, Computational protein-ligand docking and virtual drug screening with the AutoDock suite, Nature Protocols, 11(5), 905-919.

Fu, Y., Zhou, H., Wang, M., Cen, J. and Wei, Q., 2014, Immune Regulation and Anti-in flammatory Effects of Isogarcinol Extracted from Garcinia mangostana L. against Collagen-Induced Arthritis, Journal of Agricultural and Food Chemistry, 62(18), 4127-4134.

Helgren, T.R. and Hagen, T.J., 2018, Demonstration of AutoDock as an Educational Tool for Drug Discovery Travis, Journal of Chemical Education, 94(3), 345-349.

Hetényi, C. and Spoel, D. Van Der, 2002, Efficient docking of peptides to proteins without prior knowledge of the binding site, Protein Science, 11(7), 1729-1737.

McEwan, I.J. and Brinkmann, A.O., 2020, Androgen Physiology: Receptor and Metabolic Disorders, Website, https://www.ncbi.nlm.nih.gov/ books/NBK279028/, Accessed on Desember 12, 2020
Obolskiy, D., Pischel, I., Siriwatanametanon, N. and Heinrich, M., 2009, Garcinia mangostana L .: A Phytochemical and Pharmacological Review', Phytotherapy Research, 23(8), 1047-1065.

Ovalle-Magallanes, B., Eugenio-Pérez, D. and Pedraza-Chaverri, J., 2017, Medicinal properties of mangosteen (Garcinia mangostana L.): A comprehensive update, Food and Chemical Toxicology, 109(Pt 1), 102-122.

Pagadala, N.S., Syed, K. and Tuszynski, J., 2017, Software for molecular docking : a review, Biophysical Reviews, 9(2), 91-102.

Peng, C.C., Chen, C-Y., Chen, C-R., Chen, C-J., Shen, K-H., Chen, K-C. and Peng, R.Y., 2019, Renal Damaging Effect Elicited by Bicalutamide Therapy Uncovered Multiple Action Mechanisms As Evidenced by the Cell Model, Scientific Reports, 9(3392), 1-16.

Pereira de Jesus-Tran, K., Cote, P-L., Cantin, L., Blanchet, J., Labrie, F. and Breton, R., 2006, Comparison of crystal structures of human androgen receptor ligand-binding domain complexed with various agonists reveals molecular determinants responsible for binding affinity, Protein Science, 15(5), 987-999.

Puratchikody, A., Sriram, D., Umamaheswari, A. and Irfan, N., 2016, 3 - D structural interactions and quantitative structural toxicity studies of tyrosine derivatives intended for safe potent inflammation treatment, Chemistry Central Journal, 10(24), 1-19.

Ryde, U. and Söderhjelm, P., 2016, Ligand-Binding Affinity Estimates Supported by Quantum- Mechanical Methods, Chemical Reviews, 116(9), 5520-5566.

Setlur, S.R. and Rubin, M.A., 2005, Current Thoughts on the Role of the Androgen Receptor and Prostate Cancer Progression, Advance in Anatomic and Pathology, 12(5), 265-270.

Singh, A.N., Baruah, M.M. and Sharma, N., 2017, Structure Based docking studies towards exploring potential anti androgen activity of selected phytochemicals against Prostate 
Cancer, Scientific Reports, 7(1995), 1-8.

Siridechakorn, I., Phakhpdee, W., Ritthiwigrom, Promgool, T., Deachathai, S., Cheenpracha, S., Prawat, U. and Laphookhieo, S., 2012, Antibacterial dihydrobenzopyran and xanthone derivatives from Garcinia cowa stem barks, Fitoterapia, 83(8), 1430-1434.

Song, C-H., Yang, S.H., Park, E., Cho, S.H., Gong, E-Y., Khadka, D.B., et al., 2012, Structure-based Virtual Screening and Identification of a Novel Androgen Receptor Antagonist, Journal of Biological Chemistry, 287(36), 30769-30780.

Tan, M.H.E., Li, J., Xu, H.E., Melcher, K. and Yong, E-L., 2015, Androgen receptor: structure, role in prostate cancer and drug discovery, Acta Pharmacologica Sinica, 36(1), 3-23.

Tiang, N., Ahad, M.A., Murugaiyah, V. and Hassan, Z., 2020, Xanthone-enriched fraction of Garcinia mangostana and a mangostin improve the spatial learning and memory of chronic cerebral hypoperfusion rats, Journal of Pharmacy and Pharmacology, 1-16. Torres, P.H.M., Sodero, A.C.R. and Jofily, P., 2019, Key Topics in Molecular Docking for Drug Design,
International Journal of Molecular Sciences, 20(4574), 1-29.

Valdés-Tresanco, M.S., Valdés-Tresanco, M.E., Valiente, P.A. and Moreno, E., 2020, AMDock: a versatile graphical tool for assisting molecular docking with Autodock Vina and Autodock4, Biology Direct, 15(12), 1-12.

Vanommeslaeghe, K., Guvench, O. and MacKerell Jr., A.D., 2015, Molecular Mechanics, Current Pharmaceutical Design, 20(20), 3281-3292.

Wang, P., Mcinnes, C. and Zhu, B.T., 2013, Structural Characterization of the Binding Interactions of Various Endogenous Estrogen Metabolites with Human Estrogen Receptor a and b Subtypes: A Molecular Modeling Study, PLOS One, 8(9), 1-11.

Wang, Y., Tsai, M-L., Chiou, L-Y., Ho, C-T. and Pan, M-H., 2015, Antitumor Activity of Garcinol in Human Prostate Cancer Cells and Xenograft Mice, Journal of Agricultural and Food Chemistry, 63(41), 9047-9052.

Yang, R., Li, P., Li, N., Zhang, Q., Bai, X. Wang, L., et al., 2017, Xanthones from the Pericarp of Garcinia mangostana, Molecules, 22(5), 683. 